\title{
Effectiveness of Hypertonic Saline Nebulization in Airway Clearance in Children with Non-Cystic Fibrosis Bronchiectasis: A randomized control trial
}

\author{
KWDA Anuradha ${ }^{1}$, PKG Gunathilaka ${ }^{2}$, and VP Wickramasinghe ${ }^{1}$ \\ ${ }^{1}$ University of Colombo Faculty of Medicine \\ ${ }^{2}$ Lady Ridgeway Hospital for Children
}

August 7, 2020

\begin{abstract}
Abstract INTRODUCTION: Effective Airway Clearance Techniques (ACT) is the key step in the management of Bronchiectasis. The aim of this study was to evaluate the efficacy of $3 \%$ Hypertonic Saline (HS) pre-medication in ACT in children with non Cystic Fibrosis (non-CF) bronchiectasis. METHODS: Five to 15 year old children with non-CF bronchiectasis were randomized either to receive $200 \mu \mathrm{g}$ of inhaled salbutamol followed by hypertonic saline nebulization (test) or only $200 \mu \mathrm{g}$ of inhaled salbutamol, prior to chest physiotherapy which is the conventional ACT (controls) for 8 weeks. After completion of first phase both groups went through one month washout period, before being crossed over to the opposite arms in the second phase. Spirometric parameters were recorded at the end of each phase. RESULTS: Fifty two children completed the study. Baseline characteristics of the two groups were similar. A significantly higher mean improvement was seen in predicted Forced Expiratory Volume in one second(FEV1) in the HS arm during phase 1 [HS=14.15 \pm 5.50 vs. conventional $=5.04 \pm 5.55, \mathrm{p}=0.001]$ and phase II $[\mathrm{HS}=10.81 \pm 5.51$ vs. conventional $=3.54 \pm 5.13, \mathrm{p}=0.001]$. HS arm showed a significantly higher mean improvement in predicted Forced Vital Capacity(FVC) in phase $\mathrm{I}[\mathrm{HS}=13.77 \pm 5.73$ vs. conventional $=7.54 \pm 4.90$, $\mathrm{p}=0.001]$ and phase II, $[\mathrm{HS}=9.42 \pm 7.00$ vs. conventional $=4.42 \pm 4.00, \mathrm{p}=0.003)$. Mean number of exacerbations experienced by a single child during phase I ( 2 months) were significantly less $(\mathrm{p}=0,001)$ in HS group compared to that of conventional group. CONCLUSIONS: Incorporating HS nebulization into ACT is an effective strategy to improve dynamic lung volumes and morbidity in children with non-CF bronchiectasis.
\end{abstract}

\section{KEY WORDS}

Hypertonic Saline, Nebulization, Airway Clearance, Non-CF bronchiectasis

Abbreviations : ACT, Airway Clearance Techniques ;CF, Cystic Fibrosis; FEV1,Forced Expiratory Volume in one second;FVC, Forced Vital Capacity; HS,Hypertonic Saline; IS,Isotonic Saline ;pMDI,pressurized Metered Dosed Inhaler ; VHC, valved holding chamber

\section{INTRODUCTION}

Though cystic fibrosis (CF) is the commonest cause of bronchiectasis in the western world, non-Cystic Fibrosis (non-CF) bronchiectasis remains the major contributor to the burden of chronic respiratory morbidity in both developed and developing countries due to late diagnosis, limited resources to manage, and lack of research data. ${ }^{1-3}$

Diagnostic delay is highlighted as one reason for poor outcomes in non-CF bronchiectasis patients. ${ }^{4,5}$ Therefore high index of suspicion, early diagnosis and optimum airway clearance is the way forward in improving the clinical outcome in bronchiectasis. ${ }^{6}$ 
Bronchiectasis is characterized by irreversible abnormal dilatation and anatomical distortion of the bronchial tree and represents a common end stage of many nonspecific and unrelated antecedent conditions. ${ }^{7} \mathrm{~A}$ complex interplay between infection and inflammation creates a pro-inflammatory vicious cycle that progressively destructs pulmonary architecture leading to chronic bronchial dilatation which is the hallmark of bronchiectasis. ${ }^{8}$ With this pathophysiological background, management is directed at breaking this vicious cycle and facilitating the muco-ciliary clearance of secretions which will hinder the on-going bronchial damage. Therefore treatment of underlying cause and providing optimum supportive care should happen parallelly. ${ }^{9,10}$ To date, most of the treatment recommendations for non-CF bronchiectasis are extrapolated from studies done on paediatric patients with $\mathrm{CF}$ or adults with bronchiectasis. ${ }^{11-13}$ Multiple airway clearance techniques have been introduced without their value been well established. ${ }^{14}$

HS has many mucolytic mechanisms that improve the in vitro transportability of the mucus. It disrupts the structure of the mucus gel, thereby reducing its viscosity and elasticity. It also increases the osmotic activity of the surface liquid layer of the airway to facilitate drawing water into the airway lumen. In addition it helps to dissociate DNA from the mucoprotein and allows natural proteolytic enzymes to digest it. HS reaches a peak effect within about 10 minutes of administration. ${ }^{15}$

Pre medication of HS nebulizations before commencement of airway clearance technique is a well-established method in managing bronchiectasis due to $\mathrm{CF} .{ }^{16,17}$ Based on the effectiveness and safety demonstrated in $\mathrm{CF}$ patients, most of the international guidelines recommend the use of HS in the management of bronchiectasis irrespective of the aetiology. ${ }^{18-20}$ However it should be appreciated that the properties of mucus produced in $\mathrm{CF}$ patients are different from that of patients with non-CF bronchiectasis.

Apart from the absence of high quality scientific evidence on the use of HS in the management of non-CF bronchiectasis some of the available trials on adults give contradicting results. ${ }^{21,}{ }^{22}$ Yet some centres use this technique in the management of children with non-CF bronchiectasis.

The primary objective of this study was to establish whether use of HS nebulization prior to chest physiotherapy would improve the pulmonary functions reflected by FEV1, FVC and FEV1/FVC ratio as well as morbidity over a period of time.

\section{METHODS}

Study design and population: This was a randomised, cross-over study conducted at the University Paediatric Unit of the Lady Ridgeway Hospital for Children, Colombo, Sri Lanka from February 2018 to February 2020.

Children aged five to 15 years with clinically diagnosed and radiologically (High Resolution Computer Tomographic scan) confirmed bronchiectasis, without $\mathrm{CF}$, excluded by two negative sweat tests, were included in the study.

Children who were unable to comply with regular follow up, already on regular HS nebulization, diagnosed with chronic colonization of Pseudomonas spp., with a history of hypersensitivity for the medications (salbutamol, HS) or having typical extra pulmonary features of CF, were excluded.

Sample size: Due to lack of data in paediatric population with non-CF bronchiectasis on improvement of FEV1 following ACT, an interim analysis was done once the first 25 patients enrolled to conventional group and completed phase one of the protocol. Mean improvement of FEV1 of them was 5.22(SD=5.75). To detect a $10 \%$ improvement with HS with a $95 \%$ confidence interval and an $80 \%$ power, the calculated sample size was 52 (26 in each group)

Study procedure: Parents of eligible patients were explained about the study and parent information sheet was given in their preferred language. After explaining and addressing concerns informed written consent was obtained from parents and the assent from children above 12 years. Afterwards they were registered and a serial number was given. A baseline spirometry was performed and values were recorded.Spirometry was performed using portable MIRspirolab 4 spirometry system according to the ATS guidelines ${ }^{23}$.Calibration 
of the spirometer was done regularly and nose clip was applied when forced expiratory manoeuvres are performed. The best three technically acceptable blows were recorded and the best value was recorded.

Computer generated variable blocked randomization was done to allocate patient either to test arm or control arm as shown in Figure 1. Allocation concealment was done with sequentially numbered sealed opaque envelops which were opened to decide the arm of enrolled patients.

The test arm received $200 \mu \mathrm{g}$ of inhaled salbutamol followed by $3 \mathrm{ml}$ of $3 \%$ saline nebulisations prior to chest physiotherapy twice daily for 60 days during the phase I while the control arm receiving $200 \mu \mathrm{g}$ of inhaled salbutamol followed by chest physiotherapy which is the conventional airway clearance technique.

Parents were adequately trained on the usage of inhaled salbutamol with a metered dose inhaler and a spacer device, home nebulizations and technique of chest physiotherapy. Physiotherapy was given according to a uniform protocol in all children i.e. active cycle of breathing, percussion and vibration along with postural drainage and all parents were trained by a qualified physiotherapist.

Spirometric parameters and number of exacerbations after 60 days of therapy in each arm were documented and a wash out period of 30 days was applied for the two groups from 60 days to 90 days. During the wash out period children were managed with conventional ACT. Thereafter children in the two group's treatment arms were swapped (test arm to control arm and control arm to test arm) and followed up for the next 60 days and the outcome parameters were measured at the end of second 60 days. 


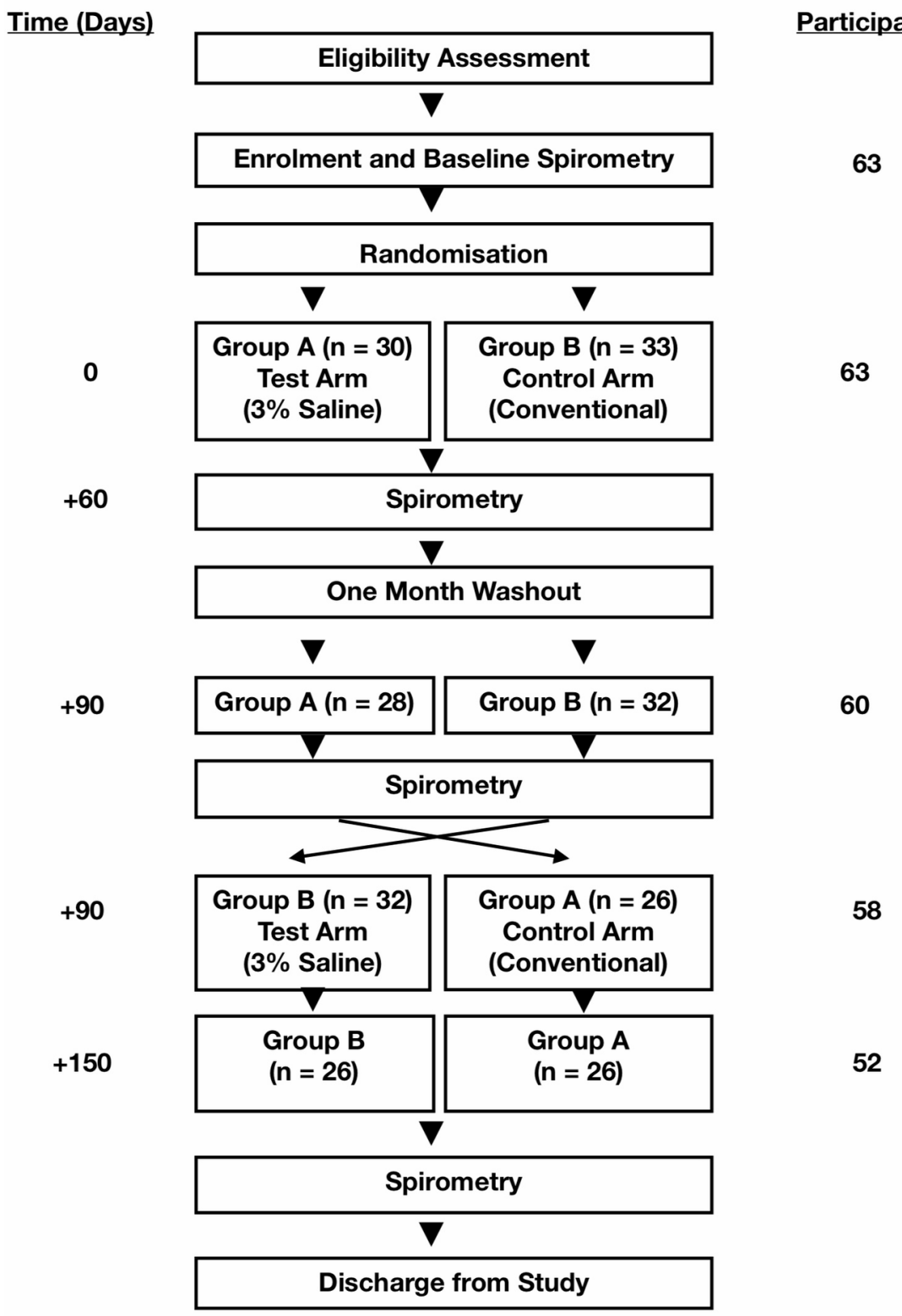

FIGURE 1 Flow of subjects in the study protocol with the time line

Statistical Analysis: Data was processed with Microsoft Excel, independent t test where Statistical significance was taken as $\mathrm{p}$ value less than 0.05 . Data was analysed with $<\mathrm{R}$ package for data analysis: $\mathrm{R}$ Core Team (2017).https://www.R-project.org, https://ggplot2.tidyverse.org

Ethics Review committee of the Faculty of Medicine, University of Colombo approved the study protocol (EC/17/151)) and the trial was registered with the Sri Lanka Clinical Trials Registry (SLCTR/2018/008) .https://slctr.lk/trials/slctr-2018-010/publications/74.

\section{RESULTS}

Sixty three children (boys26) who fulfilled the inclusion criteria were randomized but only 52 children (boys 21) completed the study protocol. There were 11drop outs at different stages of the trial but the sub analysis 
of the basic demographic parameters and baseline lung functions of them showed no significant difference from the group of children who completed the study.

Figure 1 shows the number of children in the two groups (A and B) and the total number of participants at each stage of the study. Out of the dropped out patients 3 patients found it difficult to attend the clinic due to distance. Parents of two patients who were started on HS in the initial phase were not willing to switch over to conventional (control) arm after the washout as parents felt the clinical and lung volume improvement of their children were good. Six children could not complete the second phase due to an unexpected shortage of $3 \%$ saline in the country and had to remove from the study.

Commonest aetiology of bronchiectasis among the children enrolled was post infective (33/63) and the rest consisted of primary immune deficiency related conditions $(6 / 63)$, congenital structural malformations $(3 / 63)$, post tuberculosis $(2 / 63)$, aspiration syndromes $(3 / 63)$ and aetiology was unknown in a quarter of patients(16/63).

The mean age was $9.3 \pm 2.6$ years. Table 1shows the baseline parameters of the two groups and they did not show any difference.

TABLE 1: Baseline Characteristics of the two samples

\begin{tabular}{llll}
\hline Characteristics & Group A $(\mathbf{n = 2 6 )}$ & Group B(n=26) & P value \\
\hline Male: Female & $11: 15$ & $10: 16$ & - \\
Age (Yrs.) & $9.80 \pm 2.97$ & $9.10 \pm 2.40$ & 0.42 \\
Age at the diagnosis (Yrs.) & $5.60 \pm 2.33$ & $6.37 \pm 2.60$ & 0.29 \\
respiratory rate per min & $32.15 \pm 6.64$ & $32.00 \pm 5.62$ & 0.93 \\
Heart Rate (bpm) & $99.00 \pm 12.87$ & $97.84 \pm 9.53$ & 0.69 \\
Oxygen Saturation (\%) & $95.73 \pm 2.73$ & $94.00 \pm 4.50$ & 0.38 \\
BMI SD & $-0.81 \pm 1.98$ & $-0.76 \pm 1.91$ & 0.44 \\
Predicted FEV1 (\%) & $64.35 \pm 12.90$ & $65.38 \pm 14.85$ & 0.79 \\
Predicted FVC (\%) & $63.88 \pm 9.78$ & $63.31 \pm 10.82$ & 0.84 \\
FEV1/FVC ratio & $79.34 \pm 11.34$ & $78.23 \pm 10.50$ & 0.54 \\
PEFR (\%) & $67.55 \pm 14.23$ & $69.23 \pm 12.62$ & 0.76 \\
\hline
\end{tabular}

Results are presented as mean \pm SD with a $95 \%$ Confidence Interval. HS,Hypertonic saline; BMI, body mass index;FEV1, Forced Expiratory Volume in one second;FVC, Forced Vital Capacity; PEFR, Peak Expiratory Flow Rate;bpm,beats per minute

Primary outcome measure of this trial was the improvement of FEV1 after the intervention with Hypertonic Saline nebulization prior to chest physiotherapy. The mean FEV 1 improvement of children receiving HS was higher than those receiving conventional therapy, where the difference was statistically significant at both phases of the study as shown in table 2 and figure 2.

TABLE 2: Clinical and Spirometric improvement of dynamic lung volumes in the two groups during phase I and II

\begin{tabular}{|c|c|c|c|c|c|c|c|c|}
\hline $\begin{array}{l}\text { Primary } \\
\text { Outcome }\end{array}$ & $\begin{array}{l}\text { Primary } \\
\text { Outcome }\end{array}$ & $\begin{array}{l}\text { HS } \\
\text { treatment } \\
(\mathrm{n}=26)\end{array}$ & $\begin{array}{l}\text { HS } \\
\text { treatment } \\
(\mathrm{n}=26)\end{array}$ & $\begin{array}{l}\text { HS } \\
\text { treatment } \\
(\mathbf{n}=26)\end{array}$ & $\begin{array}{l}\text { Conventiona } \\
\text { treatment } \\
(\mathrm{n}=26)\end{array}$ & $\begin{array}{l}\text { AConventiona } \\
\text { treatment } \\
(n=26)\end{array}$ & $\begin{array}{l}\text { Conventional } \\
\text { treatment } \\
(\mathrm{n}=26)\end{array}$ & P valu \\
\hline & & Pre ACT & Post ACT & $\begin{array}{l}\text { Mean } \\
\text { Improve- } \\
\text { ment }\end{array}$ & Pre ACT & Post ACT & $\begin{array}{l}\text { Mean } \\
\text { Improve- } \\
\text { ment }\end{array}$ & \\
\hline
\end{tabular}




\begin{tabular}{|c|c|c|c|c|c|c|c|c|}
\hline $\begin{array}{l}\text { Primary } \\
\text { Outcome }\end{array}$ & $\begin{array}{l}\text { Primary } \\
\text { Outcome }\end{array}$ & $\begin{array}{l}\text { HS } \\
\text { treatment } \\
(\mathrm{n}=26)\end{array}$ & $\begin{array}{l}\text { HS } \\
\text { treatment } \\
(\mathrm{n}=26)\end{array}$ & $\begin{array}{l}\text { HS } \\
\text { treatment } \\
(\mathrm{n}=26)\end{array}$ & $\begin{array}{l}\text { Conventiona } \\
\text { treatment } \\
(\mathrm{n}=\mathbf{2 6})\end{array}$ & $\begin{array}{l}\text { AConvention } \\
\text { treatment } \\
(\mathrm{n}=26)\end{array}$ & $\begin{array}{l}\text { alConventiona } \\
\text { treatment } \\
(\mathrm{n}=26)\end{array}$ & $\mathbf{P}$ valu \\
\hline \multirow{2}{*}{$\begin{array}{l}\text { Mean } \\
\text { Pre- } \\
\text { dicted } \\
\text { FEV1 } \\
(\%)\end{array}$} & Phase I & 64.35 & 78.50 & $14.15 \pm 5.50$ & 70.42 & 65.38 & $5.04 \pm 5.55$ & 0.000 \\
\hline & Phase II & 72.92 & 62.12 & $10.81 \pm 5.51$ & 71.19 & 74.73 & $3.54 \pm 5.13$ & 0.001 \\
\hline \multirow{2}{*}{$\begin{array}{l}\text { Mean } \\
\text { Pre- } \\
\text { dicted } \\
\text { FVC } \\
(\%)\end{array}$} & Phase I & 63.88 & 77.65 & $13.77 \pm 5.73$ & 63.30 & 70.84 & $7.54 \pm 4.90$ & 0.000 \\
\hline & Phase II & 62.11 & 71.53 & $9.42 \pm 7.00$ & 68.58 & 73.00 & $4.42 \pm 4.00$ & 0.003 \\
\hline \multirow{2}{*}{$\begin{array}{l}\text { Secondary } \\
\text { Outcome }\end{array}$} & Secondary & HS & HS & HS & Conventiona & aConvention & alConventiona & \\
\hline & Outcome & $\begin{array}{l}\text { treatment } \\
(\mathrm{n}=26)\end{array}$ & $\begin{array}{l}\text { treatment } \\
(\mathrm{n}=26)\end{array}$ & $\begin{array}{l}\text { treatment } \\
(\mathrm{n}=26)\end{array}$ & $\begin{array}{l}\text { treatment } \\
(\mathrm{n}=26)\end{array}$ & $\begin{array}{l}\text { treatment } \\
(\mathrm{n}=26)\end{array}$ & $\begin{array}{l}\text { treatment } \\
(n=26)\end{array}$ & \\
\hline \multirow{2}{*}{$\begin{array}{l}\text { Mean } \\
\text { Number } \\
\text { of exac- } \\
\text { erba- } \\
\text { tions/child/ } \\
\text { year }\end{array}$} & Phase I & $2.50 \pm 0.64$ & $2.50 \pm 0.64$ & $2.50 \pm 0.64$ & $7.80 \pm 1.05$ & $7.80 \pm 1.05$ & $7.80 \pm 1.05$ & 0.001 \\
\hline & Phase II & $3.90 \pm 0.74$ & $3.90 \pm 0.74$ & $3.90 \pm 0.74$ & $6.20 \pm 0.77$ & $6.20 \pm 0.77$ & $6.20 \pm 0.77$ & 0.074 \\
\hline
\end{tabular}

Improvements are presented as mean $\pm \mathrm{SD}$ with a 95\% Confidence Interval. HS,Hypertonicsaline; ACT, Airway Clearance Technique;FEV1,Forced Expiratory Volume in one second;FVC, Forced Vital Capacity;

FIGURE 2 Improvement in FEV1 during First and Second phases

FIGURE 3 shows the higher mean improvement in FVC in HS Arm of children at both phases of the study where the difference is statistically significant.

FIGURE 3 Improvement in FVC during First and Second phases

Number of exacerbations each child experienced was recorded during both phases and shown in Table 2. There was a significant difference between the two groups in the mean number of exacerbations during phase I where the lesser number of exacerbations were seen in the HS group. However no significant difference in the number of exacerbations was seen during phase II of the study in the two groups of children.

\section{DISCUSSION}

Despite having many mucolytic agents to aid ACT in bronchiectasis, research data to guide their use in children are very limited. ${ }^{24}$ Hypertonic saline as an airway hydrating treatment has not been sufficiently studied even in adults withnon-CF bronchiectasis and to the best of our knowledge we have not found any randomized trials in children with non-CF bronchiectasis that could warrant use of HS in routine management.

Results of this study on use of 3\% HS as a mucolytic agent prior to chest physiotherapy in children with non- $\mathrm{CF}$ bronchiectasis were promising.

Luis Maize Carro et al (2019) in their review on HS in non-CF bronchiectasis did not find any trials done on paediatric age group and the 3 randomized clinical trials reviewed by them were of patients more than 
18 years of age. ${ }^{25}$ Number of patients in those studies that were done by Kellett et al $(2005)^{21}$, Kellett et al $(2011)^{22}$ and Nicolson et al $(2012)^{26}$ had been 24,28 and 40 respectively with a dropout rate ranging between $10-15 \%$.

Although there was a slightly higher dropout rate (17\%) in our study, 52 completed, and some of the reasons were logistic, than individual reasons such as poor compliance.

There were no dropouts due to the adverse effects of $3 \%$ saline nebulization in this study similar to two randomized crossover trials on the use of HS (7\%) in non-CF bronchiectasis in adults. ${ }^{21,22}$ In contrary a trial done in Australia with 43 children with CF related bronchiectasis had 50\% of its dropouts due to irritating cough and worsening of haemoptysis following HS nebulisations. ${ }^{27}$

Mean age of the study group $(9.51 \pm 2.67)$ was similar to a study done in India on non-CF bronchiectetic patients $(9.6$ years $) .{ }^{28}$

The baseline mean FEV1 and FVC of both arms of the trial were between $60-70 \%$ reflecting moderate impairments, which could partly be due to the relatively late diagnosis of bronchiectasis (mean ages of diagnosis are 5.6 years in HS group and 6.3 years in the conventional group). Yet this trial demonstrated a significantly higher mean improvement in predicted FEV1 in the HS arm during both phases of the study.

A crossover trial conducted in United Kingdom which studied the effectiveness of $7 \%$ hypertonic saline nebulisations in improving lung functions of patients with bronchiectasis showed similar results to this study. The two groups of patients received a random order active HS or Isotonic saline (IS) daily for 3 months and a 4 week wash-out phase was included between phases. Mean predicted FEV1 in the trial had been $66.42 \pm 6.1$, which was very close to our study results. The improvements in FEV1 and FVC were statistically significant in favour of $\mathrm{HS}(\mathrm{FEV} 1=15.1 \pm 1.8, \mathrm{p}<0.01 ; \mathrm{FVC}=11.2 \pm 0.7, \mathrm{p}<0.01){ }^{22}$ The same study showed a significant improvement in frequency of exacerbations in favour of HS (2.14 exacerbations /year in HS group vs. 4.85/year in IS group) keeping with the frequency of exacerbations reported in our study during the first phase (2.5 exacerbations/yearn HS vs. 7.8 exacerbations /year in controls) of the trial.

In contrary, another study which had a higher baseline mean predicted FEV1( $84.8 \pm 20.5$ in HS group and $80.4 \pm 21.1$ in control group) did not demonstrate any significant improvement between the two arms after intervention. ${ }^{26}$ Therefore authors concluded that a significant improvements difficult to observe when there is a higher baseline dynamic lung function test.

Mean improvement in FEV1 and FVC between the two groups were less during phase II compared to phase I and the number of exacerbations between the two groups was also not significantly different. This may be due to the better compliance with the ACT protocol in both groups towards the end of the study period in the majority. Also it could be that after a certain improvement, the base line lung functions have improved and thereafter the rate of improvement would be less.

Murray et al in their randomized cross over trial of chest physiotherapy in non-CF bronchiectasis describes a significant improvement in all domains of lung functions in patients who underwent regular chest physiotherapy compared to the group who received no physiotherapy. ${ }^{29}$

The results of 3 trials evaluated in a systematic review done in 2017 on various mucoactive agents for chronic, non-CF lung disease have favoured HS over other agents and techniques after 3 months of administration. However, the effects had not been significant at 12 months. ${ }^{30}$ All children of the current study were continued on ACT with HS after completion of the study and the consistency of the effectiveness could be measured in future.

Most of the studies available in the published literature, which used HS, were to compare the effectiveness of Hypertonic saline as a mucocilliary agent with other mucoactive agents. Objective of our study was to compare the effectiveness of HS incorporated ACT to conventional ACT. Therefore even $0.9 \%$ saline was not used in the control arm which could improve mucocilliary activity and show clinical improvement. Being an 
open label study and an unblinded evaluation with short term follow up are some of the limitations than could be seen in this study.

\section{CONCLUSION}

This randomized control trial concludes that Hypertonic Saline $(3 \% \mathrm{NaCl})$ nebulisation prior to chest physiotherapy significantly improves FEV1 in children with non-CF bronchiectasis.Improvement in FVC and the reduction in the frequency of exacerbation were significant with HS nebulization compared to conventional physiotherapy. Therefore we recommend the use of this technique in the management of non-CF bronchiectasis and to further study this with a larger sample as well as to replicate on CF patients as well.

\section{ACKNOWLEDGEMENT}

The authors acknowledge all the children and parents who dedicatedly participated in the study and the Physiotherapy Department of Lady Ridgeway Hospital for Children, Sri Lanka. We also acknowledge Mr. Chesmi Kumbalatara, Senior Consultant, PM Square (Pvt) Limited for carrying out the statistical analysis of this study.

\section{POTENTIAL CONFLICTS OF INTEREST}

Nothing to disclose.

\section{REFERENCES}

1.Babayigit A, Olmez D, Uzuner N, Cakmakci H, Tuncel T, Karaman O.2009. A neglected problem of developing countries: Non-cystic fibrosis bronchiectasis. Ann Thorac Med. 4:21-24.

2.Chang AB.2011. Bronchiectasis: so much yet to learn and to do. Paediatr Respir Rev. 12:89-90.

3. Kapur N, Karadag B.2011.Differences and similarities in non-cystic fibrosis bronchiectasis between developing and affluent countries, Paediatr Respir Rev.12(2); 91-6.

4.Eastham KM, Fall AJ ,Mitchell L,Spencer D A.2004.The need to redefine non cystic fibrosis bronchiectasis in childhood .Thorax .59:324-327.

5. Anuradha KWDA, Gunathilaka PKG, Wickramasinghe VP. 2019.Non-cystic fibrosis bronchiectasis in children: Aetiology, clinical profile and outcome in a single unit. Sri Lanka J of Child Health.48(2):111-6.

6.Randell SH, Boucher RC.2006.Effective Mucus Clearance Is Essential for Respiratory Health, AM J Resp Cell Mol. 35(1): 20-8.

7. Kliegman RM, Stanton BMD, St. Gerne J, Schor NF, editors, Nelson Textbook of Paediatrics, $20^{\text {th }}$ edition. Philadelphia: Elsevier; 2016

8. Schafer J,GrieseM,Chandrasekaran R,2018. Pathogenesis, Imaging and clinical characteristics of CF and non-CF bronchiectasis.BMC Pulm Med.79

9.Ning W,Ming QJ,Jin-Fu.2011.Brobchiectasis management in China, What we can learn from European Respiratory Society Guidelines.Chin Med J.131(16):1891-1893

10.Chang AB, Bush A,Grimwood K.2018.Bronchiectasis in Children:diagnosis and treatment.The lancet .392(10150):866-879.

11.Poeta M,Maglione M,Borrelli M,Santamaria F. 2020. Non-cyatic fibrosis bronchiectasis in children and adolescents: Neglected and emerging issues. Paediatr Neonatol.61(3):255262.http://doi.org/10.1016/j.pedneo.2019.09.013

12. Gupta AK,Lodha R,Kabra SK. 2015.Non Cystic Fibrosis Bronchiectasis.Indian J Paediatr.82:938-944.

13.Nathan AM,de Bruyne J A,Peng K,Thavagnanam S.2017.Review:Quality of life in children with non-CF bronchiectasis.Front Paediatr.April. 
14. Snijders D, Dominguez FB,Calgaro S, Bertozzi I, Escribano A M, Perilongo G, Barbato A.2015.Mucociliary clearance techniques for treating non cystic fibrosis bronchiectasis: Is there evidence? Int J Immunopathol Pharmacol.28(2):150-159

15.Mark R, Elkins P. 2012.Mechanisms and applications of hypertonic saline.J Roy Soc Med. 20:40-43

16.Gupta S, Ahmed F, Lodha R,Gupta YK, Kabra SK. 2012.Comparison of Effects of 3\% and 7\% Hypertonic Saline Nebulization on Lung Function in Children with CysticFibrosis: A Double-Blind Randomized, Controlled Trial. J Trop Pediatr. 58( 5)

17.Eng PA, Morton J,DouglassJA, Riedler J, Wilson J, Robertson CF.1996.Short term efficacy of ultrasonically nebulized hypertonic saline in cystic fibrosis. Pediatr Pulmonol. 21 :77-83

18.Pasteur MG,Bilton D, Hill AT.2010. British thoracic society guidelines for non -CF bronchiectasis. Thorax.65(Suppl.1): il-i58

19.Chang AB, Bell SC,Paul JT et al. 2015. Chronic Suppurative lung disease and bronchiectasis in children and adults inAustralia and New zealandThoracic Society of Australia and New Zealand guidelines.Med J Aust. 202 (1): 21-23.

20.Polverino E, Goeminne PC,McDonnell MJ et al .2017. European respiratory society guidelines for the management of non cystic fibrosis bronchiectasis. Ann Thorac Med.12:135-161

21.Kellett F. Redfern J,Niven R. 2005. Evolution of nebulized hypertonic saline (7\%) as an adjunct to physiotherapy in patients with bronchiectasis .Respir Med.99:27-31

22. Kellett F. Robert NM. 2011.Nebulized 7\% hypertonic saline improves lung function and quality of life in bronchiectasis .Respir Med.105:1831-1835

23.American thoracic society guidelines on lung functions-Spirometry 2017 update www.thoracic.org

24.Chang AB.2011.Bronchiectasis: so much yet to learn and to do. Paediatr Respir Rev.12:89-90.

25. Maiz Carro L, Martienz-Garcia MA.2019. Nebulized hypertonic saline in noncystic fibrosis bronchiectasis: a comprehensive review. Ther Adv Respir Dis.13.

26.Nicolson CH, stirlingRG,Borg BM, Button BM. The long term effects of inhaled hypertonic saline $6 \%$ in non-CF bronchiectasis .Respir Med 2012;106:661-667.

27.Nicolson CHH, Stirling RG, Brog BM, Button BM, Wilson JW,Holand AE,2012.The long term effect of inhaled hypertonic saline 6\% in non-cystic fibrosis bronchiectasis. Respir Med. 106;661-667.

28.Kumar A, Lodha R, Kumar P, Kabra SK.2015.Non-cystic fibrosis bronchiectasis in children: clinical profile, aetiology and outcome. Indian Paediatr.52(1):35-7.

29.Murray M.P,Pentland J.L, HilA.Tl,2009.A randomised crossover trial of chest physiotherapy in non cystic fibrosis bronchiectasis. Eur Respir J.34: 1086-1092

30.Tarrant BJ,Maitre CLE, Romero L,Steward R,Button BR,Thompson BR,Holland AE.2017. Mucoactive agents for chronic, non-cystic fibrosis lung disease:A systematic review and meta-analysis. Respirology.22:1084-1092 . 
figures/Figure1/Figure1-eps-converted-to.pdf 


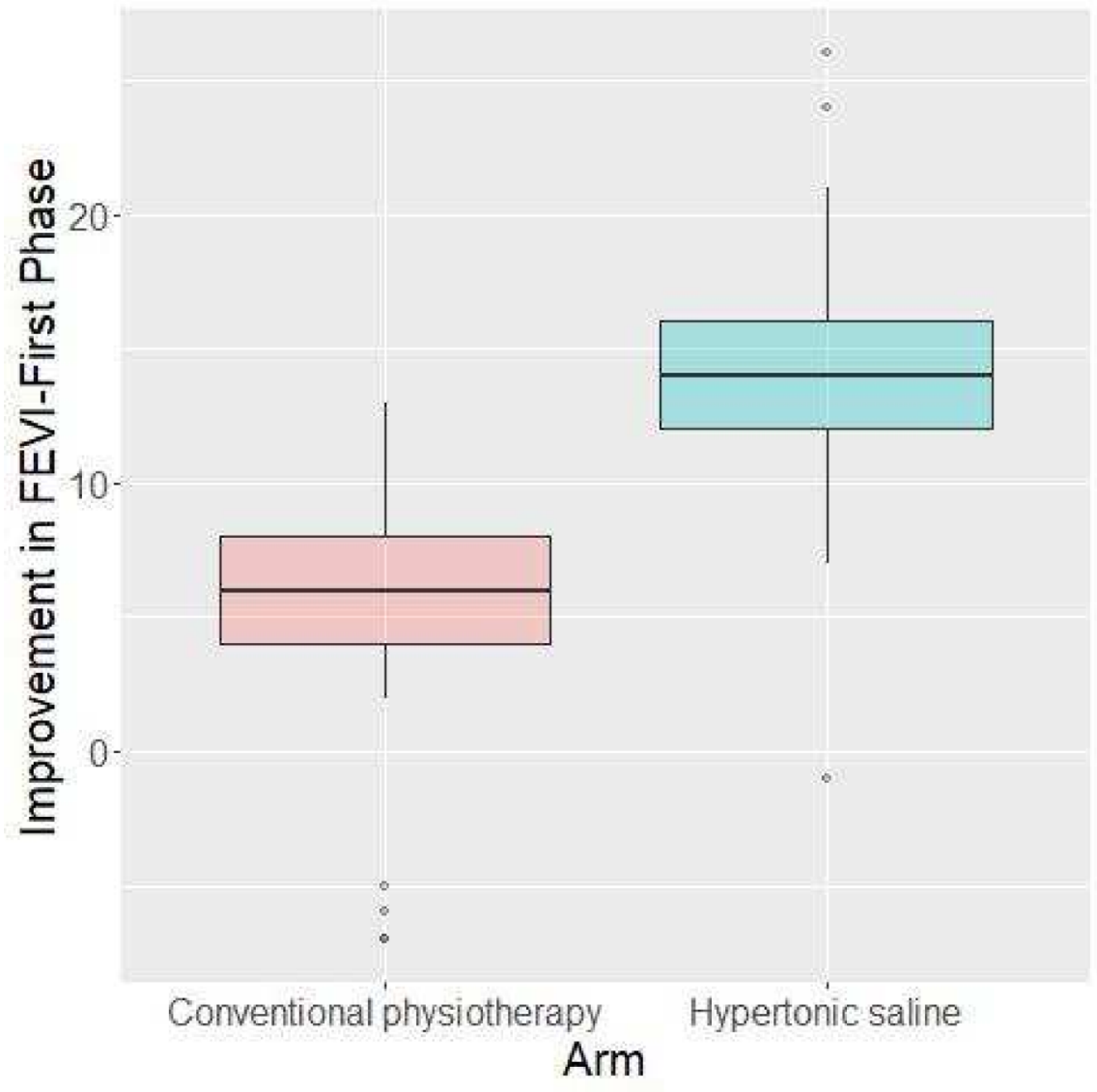


figures/FEV-1-Phase-2/FEV-1-Phase-2-eps-converted-to.pdf 


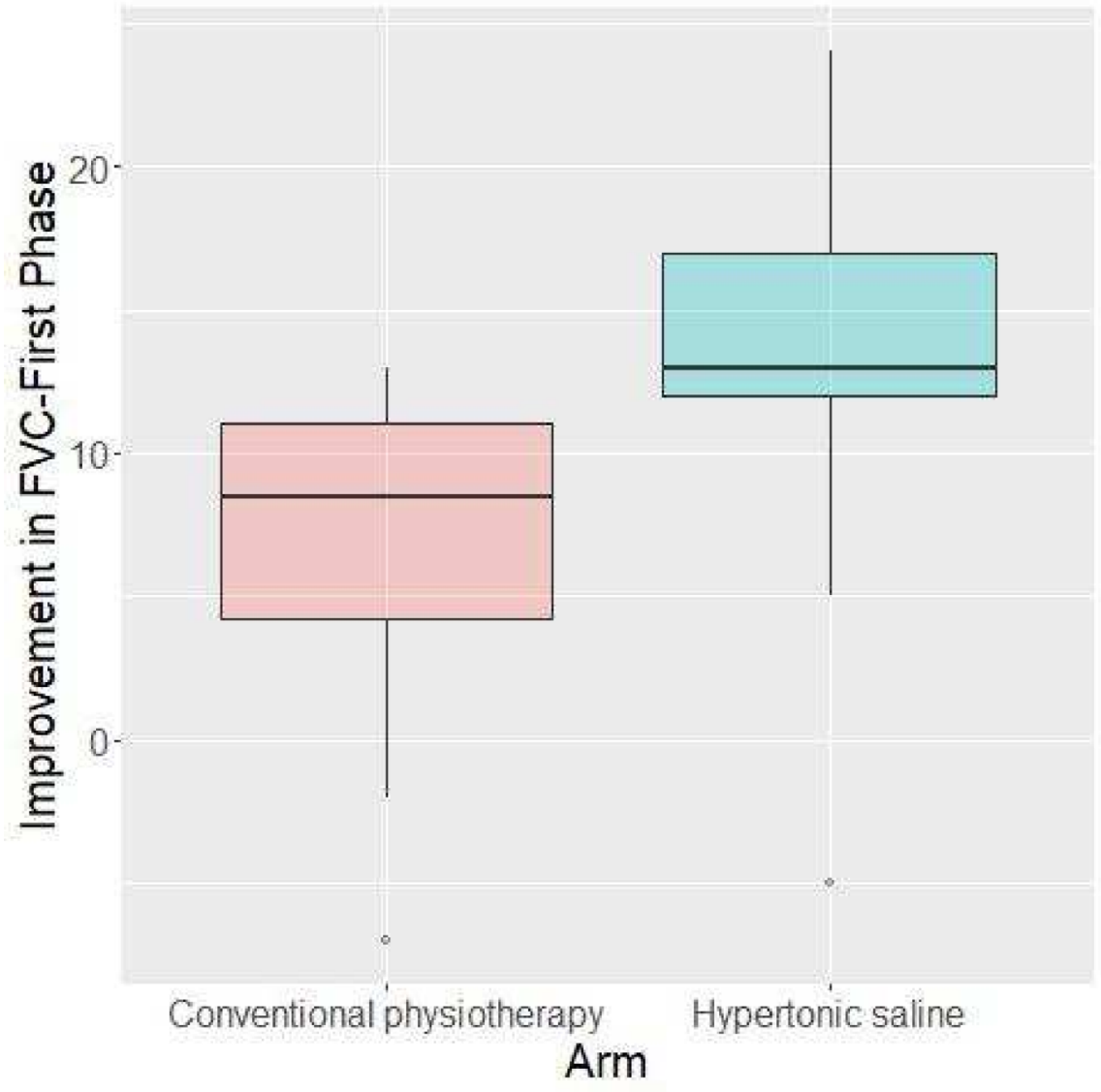




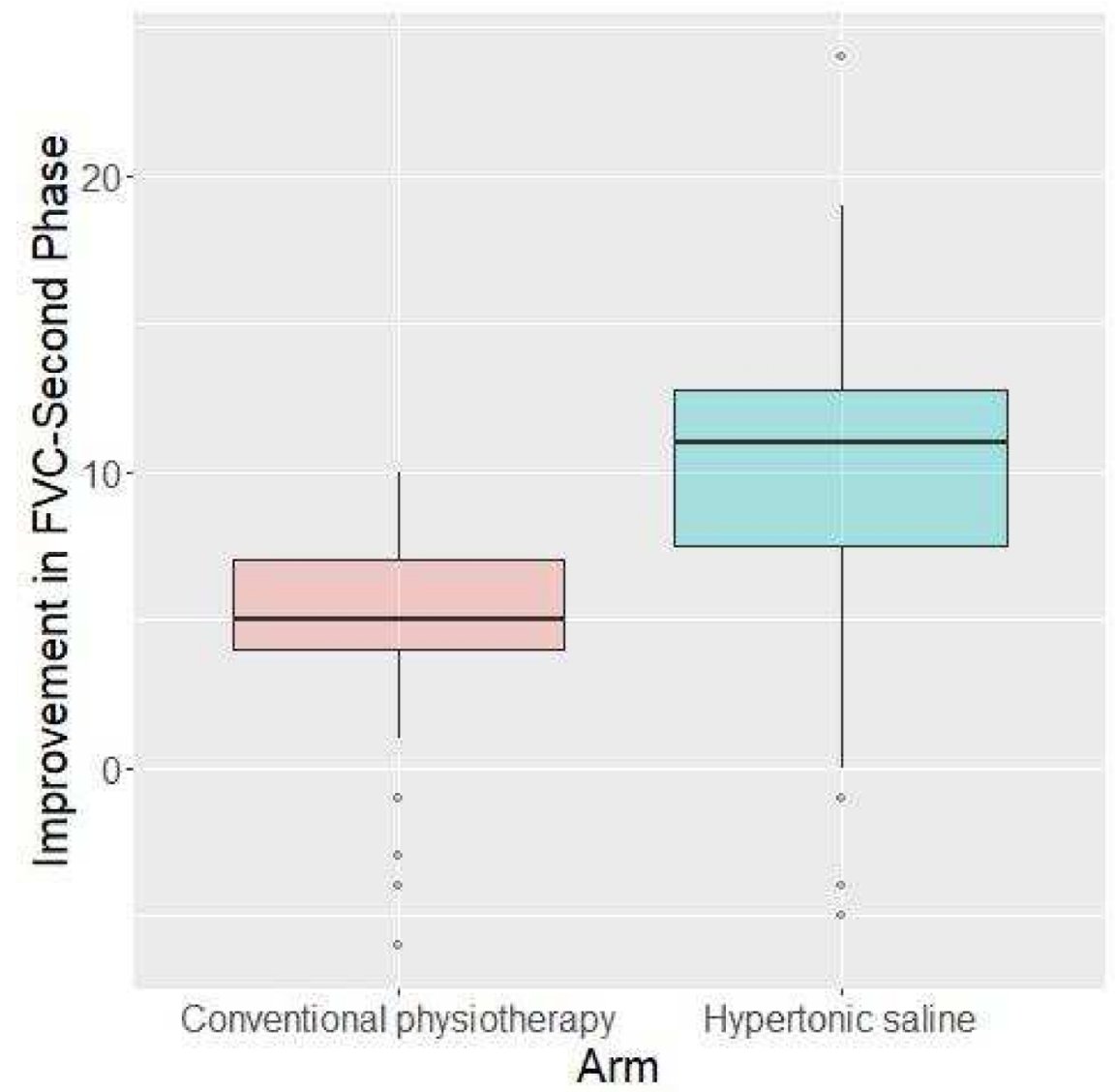

\section{Hosted file}

TABLE 1.docx available at https://authorea.com/users/349509/articles/474502-effectiveness-ofhypertonic-saline-nebulization-in-airway-clearance-in-children-with-non-cystic-fibrosisbronchiectasis-a-randomized-control-trial

\section{Hosted file}

TABLE 2. docx available at https://authorea.com/users/349509/articles/474502-effectiveness-ofhypertonic-saline-nebulization-in-airway-clearance-in-children-with-non-cystic-fibrosisbronchiectasis-a-randomized-control-trial 